\title{
ADUBAÇÃO VERDE EM CULTIVO ORGÂNICO DE HORTALIÇAS
}

\author{
Edmilson José Ambrosano'; Fabrício Rossi ${ }^{1,2}$; Luciano Grassi Tamiso ${ }^{1}$; Paulo César Tavares de \\ Melo $^{2}$; Eliana Aparecida Schammass'; Nivaldo Guirado'; João Tessarioli Neto ${ }^{2}$ (in memorian) \\ ${ }^{1}$ APTA - Pólo Regional Centro Sul, Rodovia SP 127, km 30, Caixa Postal 28, CEP: 13.400-970, Piracicaba, SP. E- \\ mail: ambrosano@apta.sp.gov.br; rossi@apta.sp.gov.br \\ ${ }^{2}$ ESALQ-USP, Depto. de Produção Vegetal, Caixa Postal 09, CEP: 13.418-900, Piracicaba-SP. \\ ${ }^{3}$ Instituto de Zootecnia, Rua Heitor Penteado, 56. CEP: 13460-000, Nova Odessa, SP.
}

\section{RESUMO}

Os produtores se interessam pelo cultivo orgânico devido à possibilidade de diminuição de custos com insumos, pela conscientização da redução de impactos ambientais e melhor funcionamento dos agroecossistemas. Neste contexto, a utilização da adubação verde torna-se essencial. Este trabalho teve como objetivo avaliar a prática da adubação verde no sistema de cultivo orgânico de hortaliças. O delineamento experimental adotado foi de blocos ao acaso, em esquema fatorial envolvendo dois fatores: adubos verdes (testemunha, tremoço-branco, chícharo e crotalária júncea) e hortaliças (alface, pimentão e cenoura), com três repetições. Os adubos verdes foram semeados a lanço e cortados após 100 dias. Sobre a palhada foram cultivadas as hortaliças, avaliando-se a produtividade de cada cultura. Em sucessão a alface foi cultivada a couve-flor. O tremoço-branco, de maneira geral, foi o melhor adubo verde para o cultivo das hortaliças estudadas. A crotalária júncea também foi eficiente para aumentar a produção do pimentão e o chícharo, para a couve-flor. Apenas a produção da cenoura não teve sua produtividade influenciada pela adubação verde.

Palavras-chave: Lactuca sativa, Daucus carota, Capsicum annuum, Brassica oleracea var. botrytis, adubo verde

\section{GREEN MANURE IN ORGANIC HORTICULTURE SYSTEM}

\begin{abstract}
Farms are interested in growing organic because of the possibility of a reduction of costs for inputs, the awareness of the reduction of environmental impacts and improved functioning of agroecosystems. In this context, the use of green manure becomes essential. The aim of this work was to evaluate the practice of green manure in the organic horticulture system. The experimental design adopted was blocks at random, factorial scheme involving two factors: green manure (control, lupine-white, lathirus and sunn hemp) and vegetables (lettuce, pepper and carrot), with three repetitions. The green manure were sown to haul and cut after 100 days. On straw Vegetables were grown on straw, evaluating the productivity of each culture. Cauliflower was grown in succession to lettuce. The lupine-white, in general, was the best fertilizer for the cultivation of green vegetables studied. Sunn hemp was effective for increasing the production of pepper and lathirus for the cauliflower. The production of carrot was not influenced by green manure.
\end{abstract}


Key words: Lactuca sativa, Daucus carota, Capsicum annuum, Brassica oleracea var. botrytis, greem manure

\section{INTRODUÇÃO}

O crescimento do mercado de produtos orgânicos se alicerça na maior conscientização dos consumidores que demandam alimentos saudáveis e seguros quanto a resíduos químicos e microbiológicos. Para o setor produtivo, o maior atrativo da produção orgânica, inicialmente, pode estar relacionado ao preço substancialmente maior alcançado no mercado, em comparação ao produto similar produzido por via convencional. No entanto os produtores se interessam por esse sistema devido à possibilidade de diminuição de custos com insumos, pela conscientização da redução de impactos ambientais e melhor funcionamento dos agroecossistemas (Diver et al., 1999). Neste contexto, a utilização da adubação verde torna-se essencial.

A definição mais difundida sobre adubação verde é aquela que diz "Denomina-se adubo verde a planta cultivada, ou não, com a finalidade precípua de enriquecer o solo com sua massa vegetal, quer produzida no local ou importada" (Kiehl, 1959). Embora seja considerada a adubação verde como o cultivo de varias espécies vegetais, naturais ou cultivadas, as leguminosas (Fabaceae) são as plantas mais utilizadas para essa finalidade, principalmente pela incorporação ao solo do nutriente nitrogênio $(\mathrm{N})$, efetuada através da fixação biológica. No Brasil, a prática da adubação verde vem sendo utilizada há mais de 30 anos com excelentes resultados sob as mais diversas condições de produção (Miyasaka, 1984), sendo observados resultados positivos, quanto ao fornecimento de $\mathrm{N}$ nos consórcios, nas culturas: do milho cultivado após a soja, (Mascarenhas et al., 1986), do algodão após a soja (Pereira et al., 1988), e do milho após o tremoço,
(Kanthack et al., 1991). Com a prática da adubação verde é possível recuperar a fertilidade do solo, proporcionando aumento do teor de matéria orgânica, aumento da capacidade de troca de cátions e aumento da disponibilidade de macro e micronutrientes. Há ainda: formação e estabilização de agregados, melhoria da infiltração de água e aeração, diminuição diuturna da amplitude de variação térmica, controle dos nematóides (Igue, 1984).

As hortaliças, de uma maneira geral, apresentam grande importância econômica. A alface, juntamente com o repolho, por exemplo, responderam por $71 \%$ das hortaliças de folhas produzidas no estado de São Paulo no ano de 2006 (Camargo, et .al., 2008). As hortaliças, devido as suas características de cultivo, estão entre os vegetais mais cultivados sobre o sistema orgânico de cultivo.

Este trabalho teve como objetivo avaliar a prática da adubação verde no sistema de cultivo orgânico de hortaliças, fornecendo conhecimentos para sua aplicação para a alface, a cenoura, o pimentão e a couve-flor.

\section{MATERIAL E MÉTODOS}

$O$ experimento foi instalado no segundo semestre de 2000, em um solo Latossolo Vermelho Eutroférrico textura argilosa, A moderado (LVef), em área agroecológica da APTA Pólo Centro Sul, em Piracicaba, SP, Brasil, cujas coordenadas são $22^{\circ} 42^{\prime} \mathrm{S}, 47^{\circ} 38^{\prime} \mathrm{W}$ e $560 \mathrm{~m}$ de altitude. $\mathrm{O}$ delineamento experimental foi em blocos ao acaso, em esquema fatorial, envolvendo dois fatores, com 3 repetições. Cada parcela foi constituída por $9,0 \mathrm{~m}^{2}$. Os adubos utilizados foram: o tremoço-branco (Lupinus albus L.), o chícharo (Lathyrus sativus L.) e a 
crotalária júncea (Crotalaria juncea L.). A testemunha foi a ausência da adubação verde. As hortaliças cultivadas foram: alface (Lactuca sativa), pimentão (Capsicum annuum) e cenoura (Daucus carota). A couve-flor (Brassica oleracea var. botrytis) foi transplanta posteriormente, em sucessão a alface. Utilizaram-se as cultivares "Verônica" de alface, "Brasília" de cenoura, híbrido "Couve-flor" e o híbrido "Magali R" de pimentão. As mudas foram produzidas em bandejas de poliestireno expandido (288 células para a alface e de 128 células para o pimentão e couve-flor).

Os adubos verdes foram semeados a lanço, conforme recomendação de Braga et al. (1998), sendo o manejo da fitomassa executado 100 dias após o semeio. Devido à desuniformidade das parcelas e para atingir quantidades satisfatórias de todos os adubos verdes, foram realizadas complementações com massa verde proveniente de outras áreas. Ao tremoço-branco foi adicionada massa verde até atingir o equivalente a $20 \mathrm{t}$ $\mathrm{ha}^{-1}$, para o chícharo adotou-se metade desta dose e para a crotalária júncea, $7 \mathrm{t} \mathrm{ha}^{-1}$. As quantidades das leguminosas foram padronizadas de acordo com seu potencial de crescimento na época cultivada, de acordo com o Boletim 200, do Instituto Agronômico de Campinas (Fahl et al., 1998). Após o corte dos adubos verdes foi realizada, segundo a análise química, a correção do solo: calagem com $1,25 \mathrm{t} \mathrm{ha}^{-1}$ de calcário agrícola, com as seguintes garantias em $\mathrm{CaO}, \mathrm{MgO}, \mathrm{PN}$ e PRNT, 37\%, 13\%, 95\% e $91 \%$, respectivamente; fosfatagem com 1,50 t ha ${ }^{-1}$ Yoorin Master $1^{\circledR}$; e adubação orgânica com $10 \mathrm{tha}^{-1}$ de composto orgânico com as seguintes garantia, relação $\mathrm{C} / \mathrm{N}$ de $25, \mathrm{~N}$ total, $\mathrm{P} 2 \mathrm{O} 5$ e $\mathrm{K} 2 \mathrm{O}$ de $0,69 \%, 1,43 \%$ e $0,30 \%$ respectivamente e $10 \mathrm{tha}^{-1}$ de húmus de minhoca. Após 10 dias foi realizada manualmente a incorporação superficial para homogenização dos canteiros. Para as culturas de alface e pimentão utilizou-se o transplantio de mudas e para a cultura da cenoura, a semeadura direta. As mudas de couve-flor foram transplantadas após a retirada da alface, para aproveitamento do efeito residual da adubação verde. A irrigação foi feita por aspersão, conforme a necessidade hídrica das culturas. Realizaram-se capinas manuais apenas quando as plantas espontâneas estavam competindo diretamente com a cultura de interesse.

A colheita ocorreu de acordo com cada cultura. Avaliou-se a massa fresca da parte aérea (MFPA) e das raízes (MFR) das alfaces por parcela. $\mathrm{O}$ mesmo procedeu-se para a cenoura, considerando-se 40 plantas por parcela. No pimentão avaliou-se a produção total $(\mathrm{PT})$ e o número de frutos por parcela (NFP), de nove plantas. Para a couve-flor foram avaliadas a massa fresca total (MFT) e a massa fresca da cabeça (MFC). Após a colheita das culturas foi coletado o solo e procedeu-se sua análise química. Os dados foram submetidos à análise de variância e as médias foram comparadas através do teste de Duncan a um nível de $5 \%$ de probabilidade.

\section{RESULTADOS E DISCUSSÃO}

A produção de biomassa dos adubos verdes foi inferior ao potencial de cada leguminosa (Tabela 1). Segundo Braga et. al., (1998) a crotalária júncea admite semeadura de outubro a março, podendo chegar até abril no caso de produção de sementes, sendo assim a semeadura feita em meados de junho prejudicou o desenvolvimento desta espécie. Quanto às outras duas espécies, o chícharo e o tremoçobranco, elas são aptas ao cultivo de inverno, contudo tiveram suas produções reduzidas devido ao baixo índice pluvial do período de cultivo e a ausência de irrigação.

O tremoço-branco foi o adubo verde que apresentou maior adaptação as condições de cultivo e produziu em torno de $1 \mathrm{~kg} \mathrm{~m}^{-2}$. Ele apresentou durante o seu ciclo 
sintomas de murcha, devido à ocorrência de cultivo das hortaliças.

Fusarium oxysporum, contudo não afetou o

Tabela 1. Massa fresca e seca da parte aérea (MFPA e MSPA) e massa fresca e seca de raízes (MFR e MSR) dos adubos verdes em $1 \mathrm{~m}^{2}$, colhidos aos 100 dias após semeio, em Piracicaba, SP.

\begin{tabular}{lcccr}
\hline Adubos verdes & MFPA & MSPA & MFR & MSR \\
\hline Crotalária júncea & \multicolumn{1}{c}{ 213,20 } & 5,80 & 13,70 & 3,30 \\
Tremoço-branco & 1051,60 & 52,50 & 84,40 & 24,60 \\
Chícharo & 296,40 & 20,10 & 31,60 & 9,60 \\
\hline
\end{tabular}

O tremoço-branco foi o adubo verde que apresentou o melhor resultado em termos de acréscimo de produtividade (MFPA) para a cultura da alface (Tabela 2), não diferindo estatisticamente do chícharo $\mathrm{e}$ da crotalária, e sendo superior à testemunha. Negrini (2007) estudou o desempenho da alface consorciada com diferentes adubos verdes, e concluiu que o tremoço-branco resultou em melhor desempenho da alface em comparação com o caupi. Em relação à MFR não houve diferenças entre os tratamentos. Para o pimentão, os dois parâmetros avaliados, PT e NFP, apresentaram resultados iguais em relação aos adubos verdes. A maior produtividade foi obtida após cultivo de tremoço, o qual não diferiu estatisticamente da crotalária júncea, sendo ambos superiores à testemunha (Tabela 2).

Tabela 2. Massa fresca da parte aérea (MFPA) e massa fresca de raízes (MFR) da alface e produção total (PT) e número de frutos por parcela (NFP) do pimentão, em rotação com os adubos verdes. Piracicaba, SP, 2000.

\begin{tabular}{|c|c|c|c|c|}
\hline \multirow{3}{*}{$\begin{array}{l}\text { Cultura } \\
\text { Adubos verdes }\end{array}$} & \multicolumn{2}{|c|}{ Alface } & \multicolumn{2}{|c|}{ Pimentão } \\
\hline & \multirow{2}{*}{\multicolumn{2}{|c|}{$\begin{array}{c}\text { MFPA MFR } \\
\text {----- gramas ----- }\end{array}$}} & \multirow{2}{*}{$\begin{array}{c}\text { PT } \\
\text {-- gramas -- }\end{array}$} & \multirow{2}{*}{$\begin{array}{c}\text { NFP } \\
\text { quantidade }\end{array}$} \\
\hline & & & & \\
\hline Testemunha & $134,88 \quad b$ & 23,00 & 1602,20 & 21,33 \\
\hline Crotalária júncea & $154,33 \mathrm{ab}$ & 20,00 & $3460,00 \mathrm{ab}$ & $45,67 \mathrm{ab}$ \\
\hline Tremoço-branco & 210,13 a & 25,33 & $4429,60 \mathrm{a}$ & 59,00 \\
\hline Chícharo & $157,19 \mathrm{ab}$ & 28,00 & 2171,80 & 30,33 \\
\hline C.V. $(\%)$ & 18,90 & 23,70 & 22,76 & 23,04 \\
\hline
\end{tabular}

Médias seguidas de mesma letra, nas colunas, não diferem entre si pelo teste de Duncan $(\mathrm{P}>0,05)$.

A cultura da cenoura não apresentou diferenças entre os tratamentos estudados (Tabela 3). Alves et al. (2004) trabalharam com incorporação de guandu no cultivo de beterraba, cenoura e feijão-vagem e não encontraram diferenças entre os tratamentos. A produtividade da couve-flor foi superior nos tratamentos com tremoço e chícharo (Tabela 3). O tratamento com crotalária 
diminui estatisticamente a produção em relação à testemunha (Tabela 3 ).

Barradas et al. (2001) estudaram o comportamento de adubos verdes de inverno na região serrana fluminense e concluíram que independente das condições de fertilidade do solo, as espécies de tremoçobranco destacam-se quanto à produção de fitomassa seca e à acumulação de $\mathrm{N}$ na parte aérea. Ambrosano et al. (2008) estudaram o consórcio do tomate cereja com o tremoço-branco e chegaram ao resultado de que $39,5 \%$ do $\mathrm{N}$ encontrado nos frutos e $27,31 \%$ de $\mathrm{N}$ da parte área provinham do adubo verde.

Tabela 3. Massa fresca da parte aérea (MFPA) e massa fresca de raízes (MFR) da alface e produção total (PT) e número de frutos por parcela (NFP) do pimentão, em rotação com os adubos verdes. Piracicaba, SP, 2000.

\begin{tabular}{|c|c|c|c|c|c|c|}
\hline \multirow{3}{*}{$\begin{array}{l}\text { Cultura } \\
\text { Adubos verdes }\end{array}$} & \multicolumn{4}{|c|}{ Cenoura } & \multirow{2}{*}{\multicolumn{2}{|c|}{$\begin{array}{c}\text { Couve-flor } \\
\text { MFC }\end{array}$}} \\
\hline & MFPA & & MFR & & & \\
\hline & \multicolumn{4}{|c|}{ 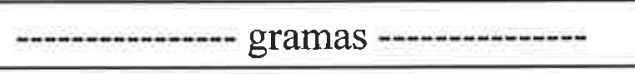 } & \multicolumn{2}{|c|}{------ gramas ------ } \\
\hline Testemunha & 2033,00 & $\mathrm{a}$ & 2676,70 & $\mathrm{a}$ & 370,40 & $\mathrm{~b}$ \\
\hline Crotalária júncea & 1890,00 & $\mathrm{a}$ & 2626,70 & a & 326,77 & c \\
\hline Tremoço-branco & 2300,00 & a & 2613,30 & $\mathrm{a}$ & 477,00 & $\mathrm{a}$ \\
\hline Chícharo & 2270,00 & $\mathrm{a}$ & 2693,30 & a & 446,50 & $\mathrm{a}$ \\
\hline C.V.(\%) & 17,84 & & 6,36 & & 4,11 & \\
\hline
\end{tabular}

Médias seguidas de mesma letra, nas colunas, não diferem entre si pelo teste de Duncan $(\mathrm{P}>0,05)$.

Ao comparar os atributos químicos do solo verifica-se que a única influência dos tratamentos foi para o $\mathrm{pH}$, que apresentou decréscimo para tratamento com tremoço (Tabela 4). Segundo Miyazawa et. al. (1993), a presença de ácidos orgânicos na massa vegetal da leguminosa pode ser a causa dessa mudança, pois o caráter anfótero das substâncias orgânicas dos resíduos vegetais faz com que o $\mathrm{pH}$ aumente em solos ácidos e diminua em condições alcalinas, sempre tendendo para valores próximos da pKa de cada ácido orgânico que geralmente está em torno da variação de 4,5 a 6,5. Observa-se também que as práticas adotadas, utilizando-se de insumos orgânicos promoveram sensivel melhora nas características estudadas, principalmente aos elementos fósforo $(\mathrm{P})$, cálcio $(\mathrm{Ca})$, magnésio $(\mathrm{Mg})$, e nas características de $\mathrm{V} \%, \mathrm{SB}$ e CTC.

Tabela 4. Caracterização química do solo inicial e final, após a colheita. Piracicaba, SP, 2000.

\begin{tabular}{lcccccc}
\hline Tratamentos & $\begin{array}{c}\mathrm{pH} \\
\left(\mathrm{CaCl}_{2}\right)\end{array}$ & $\begin{array}{c}\mathrm{MO} \\
\mathrm{g} \cdot \mathrm{dm}^{-3}\end{array}$ & $\begin{array}{c}\mathrm{P} \\
\mathrm{mg} \cdot \mathrm{dm}^{-3}\end{array}$ & $\begin{array}{c}\mathrm{Ca} \\
-\cdots----\end{array}$ & $\begin{array}{c}\mathrm{Mg} \\
\mathrm{mmol}_{\mathrm{c}} \mathrm{dm}^{-3}\end{array}$ & $\mathrm{~K}$ \\
\hline Solo inicial & 5,30 & 27,00 & 11,00 & 25,00 & 11,00 & 3,60 \\
Testemunha & $6,76 \mathrm{a}$ & $30,66 \mathrm{a}$ & $154,33 \mathrm{a}$ & $92,33 \mathrm{a}$ & $30,66 \mathrm{a}$ & $4,53 \mathrm{a}$ \\
Crotalária júncea & $6,83 \mathrm{a}$ & $29,33 \mathrm{a}$ & $175,66 \mathrm{a}$ & $89,66 \mathrm{a}$ & $35,00 \mathrm{a}$ & $4,53 \mathrm{a}$ \\
Chícharo & $6,73 \mathrm{a}$ & $31,66 \mathrm{a}$ & $158,66 \mathrm{a}$ & $92,66 \mathrm{a}$ & $32,00 \mathrm{a}$ & $4,13 \mathrm{a}$ \\
Tremoço-branco & $6,50 \mathrm{~b}$ & $32,66 \mathrm{a}$ & $159,33 \mathrm{a}$ & $84,00 \mathrm{a}$ & $31,66 \mathrm{a}$ & $5,06 \mathrm{a}$ \\
\hline C.V\% & 1,66 & 9,00 & 29,08 & 26,32 & 18,40 & 35,98 \\
\hline
\end{tabular}


... continuação da tabela 4

\begin{tabular}{lccccc}
\hline Tratamentos & $\begin{array}{c}\mathrm{S} \\
\mathrm{mg} \cdot \mathrm{dm}^{-3}\end{array}$ & $\begin{array}{c}\mathrm{H}+\mathrm{Al} \\
\mathrm{mmol}_{\mathrm{c}} \mathrm{dm}^{-3}\end{array}$ & $\begin{array}{c}\mathrm{V} \\
---\%^{\circ}---\end{array}$ & $\begin{array}{c}\mathrm{SB} \\
-----\mathrm{mmol}_{\mathrm{c} .} \mathrm{dm}^{-3}-\cdots\end{array}$ \\
\hline Solo inicial & 22,00 & 31,00 & 56,00 & 39,60 & 70,60 \\
Testemunha & $17,00 \mathrm{a}$ & $17,00 \mathrm{a}$ & $88,00 \mathrm{a}$ & $127,53 \mathrm{a}$ & $144,53 \mathrm{a}$ \\
Crotalária júncea & $19,00 \mathrm{a}$ & $15,33 \mathrm{a}$ & $88,66 \mathrm{a}$ & $129,20 \mathrm{a}$ & $144,53 \mathrm{a}$ \\
Chícharo & $19,00 \mathrm{a}$ & $28,33 \mathrm{a}$ & $82,33 \mathrm{a}$ & $128,80 \mathrm{a}$ & $157,13 \mathrm{a}$ \\
Tremoço-branco & $16,66 \mathrm{a}$ & $20,33 \mathrm{a}$ & $85,33 \mathrm{a}$ & $120,73 \mathrm{a}$ & $141,06 \mathrm{a}$ \\
\hline C.V\% & 27,39 & 47,62 & 6,25 & 23,70 & 21,06 \\
\hline
\end{tabular}

Médias seguidas de letras distintas diferem entre si pelo teste de Duncan ( $p>0,05)$.

\section{CONCLUSÕES}

A adubação verde pode contribuir para o incremento da produção de hortaliças em sistema orgânico. No entanto, a escolha da espécie que será produzida como adubo verde deve seguir orientações específicas em relação à época de cultivo, tanto referente a condições climáticas de temperatura quanto ao índice pluvial, e a possibilidade ou não de fornecimento de água suplementar.

O tremoço-branco destacou-se, nas condições do experimento, como adubo verde para o cultivo das hortaliças estudadas. A crotalária júncea também foi eficiente para aumentar a produção do pimentão e o chícharo, para a couve-flor. Apenas a produção da cenoura não teve sua produtividade influenciada pela adubação verde.

Em relação às características químicas do solo apenas o $\mathrm{pH}$ foi decrescido pelo tremoço-branco.

\section{REFERÊNCIAS BIBLIOGRÁFICAS}

AMBROSANO, E.J.; SAKAI, R.H.; SCHAMMASS, E.A.; GUIRADO, N.; ROSSI, F. et al. 2008. Uso da técnica da abundância natural de ${ }^{15} \mathrm{~N}$ na quantificação da contribuição do nitrogênio dos adubos verdes para tomate cereja em cultivo consorciado. In: SEMINÁRIO DOS PROGRAMAS
ESTRATÉGICOS DA APTA: SUSTENTABILIDADE AMBIENTAL, 2. Resumos... Barra Bonita: APTA (CDROM).

ALVES, S.M.C., ABBOUD, A.C.S., RIBEIRO, R.L.D., ALMEIDA, D.L. 2004. Balanço do nitrogênio e fósforo em solo com cultivo orgânico de hortaliças após a incorporação de biomassa de guandu. Pesquisa Agropecuária Brasileira, Brasília, v.39, 1111-1117.

BARRADAS, C.A.A.; FREIRE, L.R.; ALMEIDA, D.L.; DE-POLLI H. 2001.Comportamento de adubos verdes de inverno na região serrana fluminense. Pesquisa Agropecuária Brasileira, Brasília, v.36, p.1461-1468.

BRAGA, N.R.; MIRANDA, M.A.C.de; WUTKE, E.B.; AMBROSANO, E.J. \& BULISANI, E.A. 1998. Crotalárias ( $\boldsymbol{C}$. spectabilis, C. paulina, $C$. juncea ): In FAHL, J.I et al. Instruções Agrícolas para as Principais Culturas Econômicas, Campinas: Instituto Agronômico, 396p., p.278-279.

CAMARGO, A.M.M.M.P.; CAMARGO, F.P.; CAMARGO FILHO, W.P. 2008. Distribuição geográfica da produção de hortaliças no estado de São Paulo: participação no País, concentração regional e evolução no período 19962006. Informações Econômicas v.38, p.28-35. 
DIVER, S.; KUEPPER, G.; BORN, H. 1999. Organic tomato production. ATTRA, $25 \mathrm{p}$.

IGUE, K. 1984. Dinâmica da matéria orgânica e seus efeitos na propriedade do solo. Adubação Verde no Brasil. Fundação Cargill, Campinas, 232-67.

FAHL, J.I. et al. (Ed.) 1998. Instruções agrícolas para as principais culturas econômicas. Campinas: Instituto Agronômico, 396p.

KANTHACK, R.A.D.; MASCARENHAS, H.A.A.; CASTRO, O.M.; TANAKA, R.T. 1991. Nitrogênio aplicado em cobertura no milho após tremoço. Pesquisa Agropecuária Brasileira, Brasília, v.26, p.99-104.

KIEHL, E.J. 1959. Consorciação de Leguminosas II - Nova disposição das linhas de plantas suportes. In: CONGRESSO BRASILEIRO DE CIÊNCIA DO SOLO, 7. Anais... Piracicaba, SP.

MASCARENHAS, H.A.A.; HIROCE, R. ; BRAGA, N.R.; MIRANDA, M.A.C. de ; BULISANI, E.A.; POMMER, C.A.;
SAWAZAKI, E.; GALLO, E.; PEREIRA, J.C.V.N.A. 1986. Efeito do nitrogênio residual de soja na produção de milho. Instituto Agronômico de Campinas, Campinas, boletim técnico $58,24 \mathrm{p}$,

MIYAZAWA, M.; PAVAN, M.A.; CALEGARI, A. 1993. Efeito de material vegetal na acidez do solo. Revista Brasileira de Ciência do Solo, v.17, p.411-416.

NEGRINI, A.C.A. Desempenho de alface (Lactuca sativa L.) consorciada com diferentes adubos verdes. Piracicaba, 2007. 113p. Dissertação (Mestrado em Fitotecnia) - Escola Superior de Agricultura "Luiz de Queiroz", Universidade de São Paulo.

PEREIRA, J.C.V.N.A.; MASCARENHAS, H.A.A; MARTINS, A.L.M.; BRAGA, N.R.; SAWAZAKI, E. \& GALLO, P.B. 1988. Efeito da adubação nitrogenada em cobertura no cultivo contínuo do milho e do algodão e em rotação com soja. Revista de Agricultura, Piracicaba, v.63, p.95-108. 